\title{
El siglo de Emilio Renzi
}

\section{( Isabel Quintana ${ }^{1}$}

Instituto de Literatura Hispanoamericana, Facultad de Filosofía y Letras, Universidad de Buenos Aires / CONICET, Argentina

Recibido: 14/4/2018. Aprobado: 6/6/2018.

\author{
1. Agradezco a los directores de \\ la revista Zama por la invitación \\ a participar en este Dossier. A \\ María Inés Aldao y Carla Fumagalli \\ por la responsabilidad con la \\ que asumieron la preparación de \\ este número especial. Todas sus \\ recomendaciones y sugerencias \\ me ayudaron a editar el ensayo.
}

No es que al escribir expresemos algo.

Construimos otra realidad con palabras.

Cesare Pavese (En Ricardo Piglia. Los diarios de Emilio Renzi. Los años felices)

La literatura no es un espejo del mundo, es algo más, agregado al mundo.

Jorge Luis Borges (En Ricardo Piglia. Los diarios de Emilio Renzi. Los años felices)

\section{Resumen}

Leemos los tres volúmenes de Los diarios de Emilio Renzi como un registro de la vida del escritor en el que se problematiza el trabajo de escritura, la especificidad de la literatura y su vínculo con la política. A través del fragmento, la cita, el armado de diversas series da cuenta de las tensiones de una época y de su propia colocación en las comunidades de amigos, escritores y militantes. Por medio del extrañamiento habita su contemporaneidad e intenta descubrir ¿Cuál es la relación entre literatura y experiencia? Planteamos como hipótesis central que Los diarios constituyen un programa de escritura y vida que consiste en la ubicación siempre desajustada del escritor con respecto a los criterios literarios, al pensamiento político de sus compañeros y al tiempo postulado como el siglo de la revolución.

\section{The Century of Emilio Renzi}
Abstract
We read the three volumes of Los diarios de Emilio Renzi (The Diaries of Emilio Renzi) as a record of the life of the author, in which he questions the meaning of writing, the specificity of literature and its links with politics. By means of fragments, citations, and the assembly of mutually diverse series, the diaries seek to come to terms with
Keywords
Literature
Life
Ricardo Piglia
Diary
Disjoint

Palabras clave

Literatura

Vida

Ricardo Piglia

Diario

Desajuste 
2. En “Los años de formación: literatura y vida", Revista Landa, analizo particularmente el Tomo I de Los diarios de Renzi. the tensions of their time and the place of its author within his community of friends, writers and militants. Through the de-familiarization of his contemporary milieu, he tries to unravel the relation between literature and experience. We propose as a central hypothesis that Los diarios constitute a program of writing and life that consists on the writer's permanently disjointed location regarding literary criteria, the political thought of his colleagues and time postulated as the century of the revolution.

¿Cómo narrar? ¿Qué relación tiene la literatura con la vida? ¿Cuál es el vínculo entre el presente y el pasado? ¿Quién narra? ¿Cómo se construye un escritor? Estas preguntas recorren la obra de Piglia y fundamentalmente los tres tomos de Los Diarios de Emilio Renzi. ${ }^{2}$ Condensan las preocupaciones centrales y abren un universo de reflexiones en torno a la literatura. Desde el comienzo, el escritor Piglia/Renzi muestra una voluntad fundante: convertirse en escritor, y esa voluntad es la que se plasma implacable en la escritura de los diarios. Los cuadernos, su voraz reescritura y la edición final en los tres tomos exhiben la consistencia de ese proyecto. Un hombre puesto al servicio de la escritura, a las demandas que ello supone, al incansable ejercicio de forjar ideas, concebir un relato, tantear posibilidades, fracasar, recomenzar. El diario como registro de una vida en la que se pueden leer esas intensidades es en realidad su gran proyecto y su mejor obra. Esa postulación atraviesa los cuadernos: ¿Qué es un diario? será otro de los interrogantes que confluye con los otros y del que dan cuenta en definitiva Los diarios de Renzi.

Para ello, establece una obra que se autoalimenta incansablemente de sus obsesiones. Un mundo en que otros pueden reconocerse, pensar filiaciones o reconstruir una época. Las anotaciones aluden a diversas series: la amistad, el amor, el mundo privado, los personajes clandestinos, la política, los hechos históricos, el mundo del trabajo y la sociabilidad, reflexiones en torno a la literatura, ideas de textos futuros, citas y referencias a otros diarios de escritores (Cesare Pavese, León Tolstoi y Bertolt Brecht). Los fragmentos se ordenan en fechas precisas, en períodos específicos, al menos desde el primer tomo hasta la mitad del tercero, es un ordenamiento del que el mismo Renzi reniega porque es ajeno a la experiencia. Porque en definitiva, ¿Cómo percibimos el mundo? Y, ¿cómo nos autopercibimos? La vida acontece muy lejos de una concatenación causal. En esa tensión: entre las formulaciones más elementales de un diario (porque se escribe a diario) y las percepciones más difusas del mundo y la propia subjetividad se escriben los cuadernos. Los diarios serán el registro de un tiempo como experiencia desajustada.

\section{Extrañamiento}

He aprendido a vivir en series distintas, como vidas paralelas, sin preocuparme por la superposición. Imagino que mi prosa es el único lugar donde se cruzan todos los caminos. Para mí la clave es pensar en contra, luchar y vivir contra la corriente.

Ricardo Piglia. Los diarios de Emilio Renzi. Los años felices.

La utopía del hombre encerrado que trabaja obsesivamente en lo mismo es el modelo con el que trabaja Renzi/Piglia. Es el núcleo expansivo de los diarios y de sus relatos. Si hay una filosofía de la escritura, la misma consiste en aislarse del mundo, restringir las necesidades básicas y saltear las demandas económicas, suspender incluso la propia subjetividad. Como dice en Los diarios..., es necesario abandonar todo para escribir la vida del otro (o de uno mismo), como lo hizo Sarmiento respecto de Facundo, y como podría hacerlo él, respecto de Sarmiento: 


\begin{abstract}
He pensado que quizá una salvación para mí sería dejar todo de lado, dedicar los próximos veinte años de mi vida a estudiar por ejemplo a Sarmiento metido en bibliotecas, llenando fichas, consultando viejas ediciones, solo y sin amistades, para llegar al final de la vida con cientos y cientos de notas y fichas y armar entonces un enorme volumen de mil páginas en el que sólo se hablará de Sarmiento, sólo de Sarmiento, del Facundo quizá, sólo del Facundo, de tal modo que uno queda afuera para siempre de la vida, tan ocupado en conocer la vida de otro que se va olvidando de la suya propia y en un momento de desánimo bastará con volver a las fichas para recuperar la felicidad (2016: 184).
\end{abstract}

Renzi, en tanto personaje literario, debe resistir a toda empatía. Vive sumergido en un mundo plagado de relaciones sociales pero intenta guardar un espacio de máxima soledad. Integra una comunidad de amigos y parece fiel a ciertos ritos: charlas en los bares, caminatas por las mismas avenidas y calles, encuentros en las librerías y editoriales. Pero esa deriva por un territorio mínimo (como si fuera Tomatis en Glosay otras novelas de Saer) le garantiza una consistencia de la que toma distancia, se abisma para habitar en la extrañeza de un presente que es el suyo pero que no deja de extrañarlo. De modo programático, casi militante, pasa horas de encierro en las que busca avanzar fundamentalmente en su escritura. El aislamiento, pero también la percepción extrañada del mundo, son dos instancias de una misma experiencia en la que insiste permanecer.

La Ostranenie es para Renzi/Piglia una consigna ideológica que lo salva de las adscripciones teóricas y políticas de moda: existencialismo, estructuralismo, postestructuralismo, peronismo revolucionario, marxismo, trostkismo. Aborreciendo el existencialismo nihilista contempla la disgregación y el sinsentido desde un lugar que evita todo cinismo, habitando una suerte de anarquismo residual. El extrañamiento como procedimiento constitutivo del mundo tiene una dimensión temporal. Desde la perspectiva extrañada hay un desajuste, un desacomodamiento de la escritura del diario respecto del presente, pero también respecto del pasado. Se escribe desde el presente y en relación al presente, pero también se escribe desde el presente hacia el pasado y el futuro. Narrar en presente supone ese despliegue a modo de collage en el que conviven diversos fragmentos: lo que se recuerda del pasado y lo que se pretende llegar a ser: convertirse en escritor. Esas tres instancias temporales se imponen como problema y determinan la escritura y figura del escritor Renzi/Piglia. El pasado es el origen de los diarios (la mudanza precipitada de Adrogué a Mar del Plata) y el comienzo del mito familiar atado a la historia nacional (el padre, peronista, se refugia en Mar del Plata tras la caída de Perón).

El peronismo constituye una presencia más que fantasmática en los cuadernos, viene del pasado, atraviesa todo el presente de Renzi (el exilio de Perón) y se proyecta hacia el futuro en el regreso del líder. Tras su muerte, se reproduce en los diversos retornos y devenires (Menem sería la figura más extraña al propio peronismo). Podría postularse que el peronismo es una de las entradas fundamentales de estos diarios ligada a la figura del pater familias, las derivas trágicas y los malos entendidos. Perón, como la esfinge, pronuncia mensajes que proliferan en su significación y equívocos. Renzi es un testigo que interpela toda certidumbre política, una figura que se instala en el señalamiento de la falla, el engaño, el oportunismo, la confusión en la que navegaban sus contemporáneos. Para mantenerse a salvo desarrolla un programa de vida: evitar toda empatía con el mundo y postular modos de aproximación desde lo literario. Pero esa toma de distancia no es solamente una forma de no confluir sino de mantener la brecha respecto de toda configuración cerrada del mundo, de sostener la incertidumbre que es constitutiva de todo presente y futuro, ser contemporáneo:

La contemporaneidad es, pues, una relación singular con el propio tiempo, que adhiere a éste y, a la vez, toma su distancia; más exactamente, es esa relación con el 
3. En distintos trabajos he analizado la idea de experiencia en la obra de Piglia, quien parte en su primeras novelas, Respiración artificial y Prisión perpetua, de la idea de un vacío de la experiencia retomando la hipótesis benjamiana del fin de la experiencia, pero, a su vez, reactiva otra noción inherente a la experiencia (entre Erlebnis y Erfahrung, plantea el propio Benjamin, se debate la crisis de experiencia) que señala su carácter constructivo. La literatura, entonces, o más precisamente la novela, emprende esa tarea. A través de la figura del storyteller como personajes de sus ficciones, Piglia construye una máquina de narrar que se condensará años después en la figura de la máquina de La ciudad ausente. La experiencia no se encuentra como en Proust en una escena primordial sino que es el producto de la lucha contra su propio vacío. El escritor acomete esa tarea que se desarrolla en el proceso de escritura. En definitiva: la escritura es la experiencia. Cito en la bibliografía los artículos en los que he desarrollado este tema.

4. El "corto siglo XX" es un

concepto originalmente propuesto por el húngaro Iván Berend, pero desarrollado por el historiador marxista británico Eric Hobsbawm para referirse al período de 77 años comprendido entre 1914 y 1991, entre el comienzo de la Primera Guerra Mundial y el colapso de la Unión Soviética (Hobsbawm, 1995). tiempo que adhiere a este a través de un desfase y un anacronismo. Quienes coinciden de una manera demasiado plena con la época, quienes concuerdan perfectamente con ella, no son contemporáneos ya que, por esta precisa razón, no consiguen verla, no pueden mantener su mirada fija en ella (Agamben, 2011:18-19. Cursivas en el original).

La revolución también está teñida de un carácter trágico. En Los diarios... se alude a la decepción ante las experiencias socialistas en otros países. China y Cuba dramatizan la experiencia del desastre; es decir, el resquebrajamiento de los marcos de inteligibilidad. Por eso, la sospecha ante todo programa revolucionario esgrimido en nombre del hombre nuevo es una manera de mantener la verdad abierta, de no ceder a los nuevos dioses que auguran un cambio epocal. El más contemporáneo es el que habita en la inquietud de las respuestas no clausuradas. Y en ello se juega su escritura y su visión de lo literario. Pero esa desconfianza expresada una y otra vez en Los diarios... no puede dejar de leerse en el proceso de la edición de los cuadernos. Hay una configuración del escritor probablemente intervenida en los procesos de reescritura y edición que insiste en esa línea: desconfiar de todo, incluso de las afinidades electivas. Una demarcación que de tan enfática provoca una perturbación en los lectores.

El viaje a China se reduce a la visita al escritor Kuo Mo-jo "el escritor más famoso después de Lu Sin" (Piglia, 2016: 349), que en su insilio se dedica a caligrafiar poemas de Mao Tse Tung: la copia como réplica alude a un estado de la cultura y la vida. El encierro y la pulsión a la repetición soslayan un límite pero también la perseverancia cuando las condiciones para la libertad se restringen. Piglia/Renzi traslada a la lectura del maoísmo una imagen constitutiva de su poética: el solitario, el desterrado, el loco que trabaja obsesivamente en una réplica del mundo. En su lucha contra el vacío de la experiencia (la imposibilidad de escribir) Kuo Mo-jo se impone trabajar con la copia y hacerla proliferar. En el repliegue y la continuidad se sostiene una fidelidad que agrega un sentido nada nítido al mundo. Lo que queda en Los diarios... de su experiencia en la China comunista de los '70 es este pequeño relato (nada sabemos del diario escrito a propósito de dicho viaje). ${ }^{3}$

Sin duda, lo elidido en Los diarios... es de tal magnitud que señala una posición extrañada del escritor respecto de esos años. Se establece una doble colocación: la de la distancia en simultaneidad con los acontecimientos, y la de la distancia a partir de la reescritura. Muchas, seguramente, habrán sido las decisiones que Piglia (y ya no Renzi) decidió tomar en las intervenciones constantes a sus diarios, después de todo la reescritura es parte constitutiva de esta gran obra en marcha. En términos de posicionamientos intelectuales, políticos y afectivos, Los diarios... trabajan con un cierto malestar y configuran una imagen de escritor que se mueve en una delicada ética a la que parece nunca traicionar.

Habrá que esperar hasta el tercer tomo -desde 1982 ha dejado de escribir en los cuadernos-, la referencia explícita a aquello que definitivamente marcó al siglo XX: "Vivíamos en la inminencia del cambio de una época, en la ilusión de asistir a un cambio de civilización" (2017: 183). Ese siglo que, según postula Eric Hobswan a quien retoma Badiou en El siglo, se despliega desde 1914 hasta 1989: desde la Primera Guerra Mundial hasta la caída del Muro de Berlín, y, con ello, el fin de las utopías revolucionarias. ${ }^{4}$ Esta invocación a un nosotros desde el presente de la escritura (treinta años después de sus últimos diarios) introduce una nueva perturbación en el lector. Aquella resistencia declarada y programática a no ingresar en ninguna nominación colectiva que constituía una de las marcas epocales: el partido, la clase obrera, el proletariado, los intelectuales, se diluye brevemente en las últimas páginas. Ese nosotros se hace cargo de un cambio inminente y se congrega en torno a lo intempestivo como fuerza que produce la ruptura absoluta con la dimensión progresiva de la historia. El tiempo veloz del siglo XX opone al tiempo demorado del XIX, en su lenta marcha hacia un futuro mejor, el presente de 
un cambio radical. Esa es justamente la marca de época y conforma la vivencia de lo contemporáneo: "Lo contemporáneo es lo intempestivo" (Agamben, 2011: 17). ${ }^{5}$ Entonces, en otro tiempo, en el presente de Un día en la vida, Piglia/Renzi explicita esa vivencia con respecto al pasado: el cambio en los ‘70 era inminente y brutal, pero en nombre del hombre nuevo ese nosotros debía confrontarse con lo real. Como plantea Badiou: "Hasta el último minuto el siglo habrá sido el siglo del advenimiento de otra humanidad, de un cambio radical de lo que es el hombre" (2015: 22).

Los diarios... son ese recorrido que soslaya la experiencia extrema propia del siglo XX en la que confluyeron amigos y compañeros. Un siglo que anuncia la plena realización de los proyectos revolucionarios junto con la aparición de los espectros de Marx. ${ }^{6}$ Renzi habita con gran malestar ese tiempo a través de una escritura que bordea con desconfianza los anuncios de una nueva humanidad. Entonces, es la distancia cronológica la que le permite enunciarse en un colectivo al final de su vida en el siglo XXI: "Vivíamos en la inminencia del cambio de una época" (Piglia, 2017: 183). La distancia desplegada en Los diarios... (al menos en los dos primeros volúmenes) parece diluirse en este breve ensayo de la segunda parte del último volumen, al reconocer las expectativas compartidas con sus pares. Trae al presente los fantasmas (la inminencia de la revolución), junto con los espectros (la traición), que no han dejado de asolar su escritura. El siglo que habitó Piglia/Renzi fue el de la realización inminente de la promesa y de su frustración.

\section{El presente de la literatura}

¿Cómo estar en el presente? ¿Cómo llegar a ser contemporáneos de nuestros contemporáneos? Nosotros hemos resuelto ese dilema: Saer o Puig o yo mismo estamos en diálogo directo con la literatura contemporánea y, para decirlo con una metáfora, a su altura.

Ricardo Piglia. Los diarios de Emilio Renzi. Los años felices.

Si en el plano político y vivencial lo contemporáneo acontece como ocultamiento y no como plena iluminación, ¿de qué es contemporánea la literatura? Desde la generación del '37, Argentina, pero también el resto de América Latina, padeció de ese desajuste entre los modelos literarios importados y su adaptación local. Renzi anuncia la final paridad entre centro y periferia. Un sentimiento común a la generación del boom de la que busca diferenciarse ya que esa mayoría de edad estaría dada por su propia genealogía: Borges, Arlt, Puig, Saer y él. ¿Cuál sería ese diálogo imaginado? ¿Cómo sería ese reconocimiento en una temporalidad anterior a la consagración, al menos de Saer y luego de Piglia (Borges es el único hasta ese momento traducido y Puig comenzará a serlo en los próximos años)? También aquí se trata de un gran gesto, una intervención en el campo cultural que dictamina sobre el estado de la literatura nacional y latinoamericana colocando en la vanguardia solo a unos pocos. ${ }^{7}$ Si en Brasil los debates sobre la literatura nacional tuvieron un gran apogeo en los años '70 dando lugar a diversos posicionamientos y torsiones respecto de esa problemática relación entre la metrópoli cultural y sus respectivas periferias, el joven escritor argentino salda bruscamente un largo debate sobreimprimiendo a la contemporaneidad de los escritores del boom la de su propia estirpe. En esta región del mundo, la empresa es gigante porque no sólo se trata de pensar una revolución política sino también cultural. Si la tensión entre los modelos extranjeros readaptados a la literatura local parece haberse superado, ¿cómo se llega a esa mayoría de edad? Allí operan diversas consideraciones que más tarde se plasmarán en el mítico seminario dictado por Piglia a fines de los 80: Las tres vanguardias (Juan José Saer, Manuel Puig y Rodolfo Walsh). Uno de los grandes ejes que atraviesa la escritura de estos autores es la relación
5. Agamben cita en este párrafo a Barthes quien refiere, a su vez, a Nietzsche.

6. Derrida en Espectros de Marx propone las figuras del fantasma y el espectro para marcar una distancia y al mismo tiempo recuperar la promesa de la revolución en tanto es una justicia inalcanzable a la que, sin embargo, se debe apelar permanentemente.

7. Al escritor David Viñas definitivamente lo ubica en el siglo XIX. 
entre literatura y vida; tres modos absolutamente diferentes de interpelar los materiales de la realidad y tensionar las formas narrativas. La literatura es un espacio de experimentación, cada uno de estos escritores interviene en la tradición literaria y produce otras formas de narrar. Es decir, realizan un corte que implica un doble movimiento: una relectura desplazada de la tradición (a la que, a la vez, se la obliga a leer desviadamente) y una renovación de la prácticas literarias. La puja con el realismo clásico, el ingreso de materiales bastardos, la sensibilidad respecto de los diversos repertorios de la oralidad, la pregunta insistente por cómo narrar forman parte de estos universos literarios que tanto seducen al autor de Respiración artificial. En los Los diarios...Los años felices, Renzi/Piglia declara ese corte a partir del cual él mismo se inscribe inaugurando su propia literatura en la que lo que importa "no [es] lo que se dice, sino cómo se hace la literatura" $(2015,216)$. En ese trabajo que el escritor realiza sobre la oralidad se plantea una literatura que vendrá, postulación que constituirá una de las tesis de las Tres propuestas para el próximo milenio (2001). La literatura del futuro que imagina en los albores del 2000 es la que se inscribe en la tradición iniciada por Walsh. Piglia hace un uso anacrónico de las propuestas a su vez anacrónicas de Benjamin en torno a la figura del narrador. En dicho ensayo, resucita y proyecta en el siglo XXI la supuesta práctica extinguida de la ficción oral, como también trabaja con esas formas residuales en sus propias ficciones. Piglia observa una potencia narrativa cuya máxima condensación es la máquina de La ciudad ausente (1992). La contemporaneidad supone este uso de lo residual de lo anacrónico, como un repertorio que se resignifica en el presente.

Desde estas premisas trabaja su propio diario apelando a una supuesta inmediatez, a la no mediación y al registro minucioso de datos. En los cuadernos, las listas son numerosas, no hay justificación más que la de ordenar el desorden. Busca destilar la escritura de todo sentimentalismo, desafectarla, colocarse como mero observador y desde allí desestructurar las formas. Los cuadernos son el espacio en donde todo confluye, convive, se interpela: lo político, las citas de escritores, la vida social y familiar, los proyectos de novelas, el registro de lo cotidiano, los microrrelatos. Los diarios... constituyen una gran obra en marcha, un texto infinito que se autoalimenta incansablemente en las transcripciones, reescrituras, comentarios e intervenciones que actúan intertextualmente en sus propias ficciones (en los cuadernos leemos los borradores de Plata Quemada o Respiración artificial), un texto experimental, que nos permite ingresar al laboratorio del escritor, observar sus derivas, dilemas y resoluciones textuales. En el centro de Los diarios..., se dibuja la figura del escritor Renzi/Piglia.

\section{Formas de la clandestinidad}

Su proyecto literario supone determinadas condiciones de posibilidad sobre las que también reflexiona en Los diarios.... En los primeros dos tomos, el dinero es uno de los grandes centros reflexivos que condiciona su producción y determina una ideología. Por eso, el anarquismo cristiano de Tolstoi es atrayente, es una posición que lo conduce a renunciar a la escritura para convertirse en zapatero, porque el escritor ruso encuentra allí una utilidad de la que carece la literatura. En este sentido, Piglia/ Renzi es lo contrario de Tolstoi, ya que al reducir su economía aumenta la posibilidad de escribir. Pero también hay otro ideal que se dibuja en las diferentes anotaciones de los cuadernos, la idea de que pueda prescindir del trabajo o de los numerosos oficios (profesor, traductor, editor) y tener garantizado el dinero para vivir: una beca o un trabajo mejor remunerado. En estos cuadernos de las primeras décadas, el dinero y la propiedad privada conforman una carga de la que se busca escapar y, al mismo tiempo, forman parte de la vida: ganar dinero, alquilar, quedarse sin dinero, volver a alquilar. En esa puja por garantizar las condiciones materiales de existencia, lucha por recluirse y continuar escribiendo. Sus modelos de héroes son el revolucionario 
que renuncia a los valores burgueses para vivir en la clandestinidad (aunque también es crítico de las prácticas guerrilleras), y el delincuente (el que roba para vivir). Ambos se autoexcluyen del sistema económico, viven vidas paralelas en nombre de un ideal. Dos amigos encarnan esa figura de la heroicidad; ambos entran y salen de la cárcel y lo van a visitar. Una serie de Los diarios... se arma en torno a estas figuras mientras inicia la investigación del asalto en Tigre por una banda que luego huye a Montevideo. Esa investigación perdura en el tiempo y es el origen de Plata quemada, que en los primeros años se llama Respiración artificial (como su posterior novela). Un borrador que luego guarda hasta su posterior publicación pero en el que trabaja casi veinte años.

Pensar en otras posibilidades de circulación del dinero, en su interrupción, en el colapso de su eliminación (como la plata que queman los ladrones que resisten en un departamento en Montevideo) es una práctica a la que apela para pensar a contrapelo del funcionamiento social. En esta otra circulación no habría (es decir, intenta que no haya) una construcción romántica ya que lo bajo, lo sucio es parte de la heroicidad, de esa otra zona también constitutiva de la sociedad. De allí, la fascinación por la figura de Puig, más que por la de Walsh, por ese espacio de clandestinidad y sordidez en el que se mueve su amigo y que inaugura otra entrada de los cuadernos: la homosexualidad, origen de "El laucha Benítez cantaba boleros" (1969). Entonces, su programa literario consiste en leer otras series, armar otras circulaciones incluso, como vimos, a contrapelo de la doxa marxista. La mirada estrábica a la que se refiere mira siempre en dos direcciones, o aparece desviada. El mundo no es nítido, ni tampoco lo son las relaciones o vínculos sociales y económicos; la literatura es también parte de esa perturbación.

\section{Final}

En el plano de la temporalidad, la novela sería la serie de los momentos de crisis y del tiempo que resta, de la dilación. El cuento sería [...], el momento de la revelación, de la epifanía -incluso de la epifanía negra-. Sobre todo el cuento fantástico.

Ricardo Piglia. Entrevista con Marcelo Cohen en Otra parte, no 10.

En un diálogo con Marcelo Cohen, Piglia plantea cómo los géneros literarios suponen un determinado cierre para las historias que narran. Son relatos que trabajan con la inminencia de un fin, una temporalidad constitutiva de la forma (epopeyas, relatos apocalípticos, utopías, ciencia ficción pero también el policial). A partir de allí, es posible realizar experimentaciones que piensan desviaciones, derivas, postergaciones infinitas de un final. El tiempo del arte o de la escritura, además, se separa del tiempo de la vida, se encuentra en otra dimensión, se produce en un ritmo ajeno al ritmo de lo cotidiano: "El arte es una actividad imposible desde el punto de vista social porque su tiempo es otro, siempre se tarda demasiado (o demasiado poco) para hacer una obra" (Piglia, 1999: 106). El desfase temporal que se produce entre el tiempo específico en el que se origina produce la ficción, y el tiempo externo puramente convencional, vuelve a tensionar la experiencia de escritura y a acentuar su descolocación. Porque en definitiva, ¿quién decide que una obra esté terminada? ¿De quién depende decidir que una historia llegó a su fin? Piglia planteará que "los finales son formas de hallarle sentido a la experiencia" (2010: $\mathrm{s} / \mathrm{n}$ ). La escritura se mueve a la vez en un plano formal (la forma determina un determinado cierre) y en otro mundano, que irrumpe o impone un reacomodamiento de la forma.

Los diarios... son el registro del tiempo de la vida y de la escritura. Constituyen el tiempo de espera, una demora extendida hasta el momento de su consagración (y 
que, paradójicamente, llega en el momento del golpe militar, en 1976, cuando recibe un premio por su cuento "El laucha Benitez..."). Y también son el registro de un tiempo elidido, desde 1982 ha dejado de escribir los diarios y sus referencias al tiempo posterior llegarán en el tercer volumen como fragmentos, relatos o en los prólogos incorporados a los otros tomos. Frente al registro minucioso de los diarios escritos desde 1957 a 1982, Un día en la vida (segunda parte del último volumen) se ordena de otro modo: desaparecen las fechas y proliferan los fragmentos que retoman series de los diarios. En ellos se escenifican las tensiones de un género que es poroso y abierto y que continuamente lleva a la reflexión de su propio final: ¿cómo termina un diario? ¿Concluye con la muerte o suicidio del escritor? ¿O finaliza a partir de una operación arbitraria tan simple como dejar de escribir? En la redacción de un diario se pone en evidencia la tensión entre escritura y vida porque esa es su materia. La amenaza está siempre presente en Los diarios..., casi por definición, y se despliega desde plano especulativo (son abundantes las reflexiones sobre el suicidio de Pavese) al de la experiencia, cuando aparece la enfermedad. Esa tensión se exaspera en Los diarios... cuando lo real se impone y Piglia emprende la tarea de editar, reescribir, concluir su obra. El tiempo de la vida (que señala su fin) irrumpe y obliga a apurar los ritmos de trabajo. Los diarios concluyen históricamente en 1982 (mitad del tercer volumen) y luego se despliegan en relatos, fragmentos, citas, incorporando un final con "La caída" en el último volumen. La reescritura se convierte hacia el final de la propia vida del escritor en una actividad proliferante (mientras ordena, reordena, edita otras antologías, corrige seminarios y los publica, etc.) y conclusiva. La inminencia del final se impone y obliga a tomar decisiones: cortar, darle forma, intervenir, dejar todo terminado, escribir un cierre. Un final que nos envía nuevamente a Los diarios... y a toda la literatura de Piglia; se ha formado un tejido que nos mantiene en un movimiento de retornos permanentes. Finalmente, Los diarios... son la plasmación y el testimonio de una utopía literaria: la de quien ha vivido en torno a su escritura y ha inaugurado un mundo a través de la voluntad extrema de hacer una obra. Una pasión sostenida en el tiempo: "Siempre quise ser sólo el nombre que escribe", "El genio es la invalidez" (2017, 294). Así, concluyen los diarios. 


\section{Bibliografía}

》 Agamben, G. (2011). Desnudez. Buenos Aires: Adriana Hidalgo.

" Agamben, G. (2001). Infancia e Historia. Buenos Aires: Adriana Hidalgo.

"Badiou, A. (2015). El siglo. Buenos Aires: Manantial.

"Benjamin, W. (1989). Discursos Interrumpidos I. Buenos Aires: Taurus.

"Benjamin, W. (1988). Poesía y Capitalismo. Iluminaciones II. Madrid: Taurus.

"Derrida, J. (2012). Espectros de Marx. El Estado de la deuda, el trabajo del duelo y la nueva internacional. Madrid: Trotta.

» Jay, M. (2009). Cantos de experiencia. Variaciones modernas sobre un tema universal. Paidós: Buenos Aires.

»Piglia, R. (1965). “Literatura y Sociedad”. Literatura y Sociedad 1.1, pp. 1-12.

»Piglia, R. (1969). “El laucha Benítez cantaba boleros”. En El cuento argentino. Antología. Buenos Aires: Centro Editor de América Latina, pp. 239-249.

" Piglia, R. (1974). “Roberto Arlt: La ficción del dinero”. Hispamérica III. 7, pp. 25-28.

»Piglia, R. (1978). “La prolijidad de lo real”. Punto de vista 3, pp. 26-28.

"Piglia, R. (1980). Respiración artificial. Buenos Aires: Pomaire.

"Piglia, R. (1986). Crítica y Ficción. Santa Fe: Universidad Nacional del Litoral.

»Piglia, R. (1988). Prisión Perpetua. Buenos Aires: Sudamericana.

» Piglia, R. (1992). La ciudad ausente. Buenos Aires: Sudamericana.

»Piglia, R. (1997). Plata quemada. Buenos Aires: Planeta.

"Piglia, R. (1999). Formas breves. Buenos Aires: Temas.

»Piglia, R. (2000). Crítica y Ficción. Buenos Aires: Seix Barral.

»Piglia, R. (2001). Tres propuestas para el próximo milenio (y cinco dificultades). Buenos Aires: Fondo de Cultura Económica.

»Piglia, R. (2010). “La narración como inminencia del cierre”. En Revista Otra Parte, $\mathrm{N}^{\circ}$ 21, Buenos Aires, primavera. Disponible en <http:// revistaotraparte. $\mathrm{com} / \mathrm{n}^{\circ} / \mathrm{C}_{2} / \mathrm{BA}-21$-primavera-2010/la-narracion-como-inminencia-del-cierre> (Consulta: 15-2-2018).

»Piglia, R. (2015). Los diarios de Emilio Renzi. Años de formación. Buenos Aires: Anagrama.

»Piglia, R. (2016). Los diarios de Emilio Renzi. Los años felices. Buenos Aires: Anagrama.

» Piglia, R. (2017). Los diarios de Emilio Renzi. Un día en la vida. Buenos Aires: Anagrama.

"Quintana, I. (2001) Figuras de la experiencia en el fin de siglo: Cristina Peri Rossi, Ricardo Piglia, Juan José Saer y Silviano Santiago. Rosario: Beatriz Viterbo.

"Quintana, I. (2004). "Historia, literatura y experiencia en la obra de Ricardo Piglia”, en Ricardo Piglia: Una poética sin límites, comp. por Adriana Rodríguez Pérsico con la colaboración de Jorge Fornet, Pittsburgh: Instituto Internacional 
de Literatura Iberoamericana, serie ACP (Antonio Cornejo Polar), Universidad de Pittsburgh, pp. 161-175.

"Quintana, I. (2010). “La sonámbula: Imágenes y sueños de la ciudad futura (literatura y cine): biopolítica y ciencia ficción", Dossier / Ricardo Piglia: reescritura y crítica-ficción, Revista electrónica Orbis Tertius, Universidad de La Plata año XV 16 (2010), pp. 1-6.

»Quintana, I. (2017). “Los años de formación: literatura y vida”. Adriana Rodríguez Pérsico (comp.) Los lugares de la literatura. Espacios críticos sobre Ricardo Piglia. En Revista Landa, núm. 5.2, pp. 229-239. Brasil, Universidad de Santa Catarina. Disponible en <http://www.revistalanda.ufsc.br/vol-5-n2-2017>.

»Schwarz, R. (1973). “As ideas fora do lugar”. En Estudos Cebrap, núm. 3, pp. 149-162.

"Schwarz, R. (200o). “Prólogo". En Ao vencedor as batatas. Forma literária e processo social nos inicios do romance brasileiro. San Pablo: Livraria Duas Cidades, pp. 9-32. 